\title{
- The use of invasive techniques, angiography and indicator dilution, for quantification of valvular regurgitations
}

\author{
H. P. Krayenaueht, M. Ritter, O. M. Hess and H. Hirzel \\ Medical Policlinic, Cardiology, University Hospital, 8091 Zurich, Switzerland
}

1 KEY WORDS: Mitral and aortic regurgitation, thermodilution, left ventricular biplane cineangiography.

Angiographic techniques have been used for the quantification of mitral or aortic and rarely tricuspid regurgitation.

Mitral or aortic regurgitant volume per beat and the regurgitation fraction $\left(f_{e o}\right.$ and $f_{m}$, respectively) are obtained from the angiographic determination of total left ventricular stroke volume (TSV) and forward stroke volume (FSV) estimated by a different technique. Although this procedure is generally accepted as the gold standard for quantification of left heart regurgitations, there are several limitations: In the presence of mitral and aortic regurgitation no separate quantification of $f_{\infty}$ and $f_{\mathrm{m}}$ is feasible; heart rate at the time of determination of FSV (from Fick or dye dilution cardiac output) and of TSV (angio) may be different; there is a tendency to consistently overestimate stroke volume by angio techniques; repeated estimations of TSV bV angio are influenced by the circulatory effects of the contrast dye. In contrast indicator dilution techniques, where upsiream and downstream sampling allow the simultaneous estimation of forward and regurgitant flow, the accuracy of the determination of FSV is well established and repeated estimations of $f_{\alpha_{0}}$ and $f_{m}$ are possible because the indicators do not have cardiovascular effects. These methods are, however, crucially dependent on thorough mixing of the regurgitant volume with the blood in the upstream chamber.

In 23 patients with isolated aortic regurgitation there was a positive correlation between $f_{\infty 0}$ evaluated by thermodilution and $f_{\text {co }}$ determined by the biplane angio-Fick method $(r=0.59)$. $f_{\text {co }}$ by thermodilution averaged 0.40 and $f_{\infty}$ by angio-Fick $0.46(N S)$. In 23 patients with isolated mitral regurgitation there was also a positive correlation between $f_{m}$ determined by thermodilution and $f_{m}$ determined by angio-Fick $(r=0.71)$. However, $f_{m}$ by thermodilution was consistently smaller than $f_{m}$ by angio-Fick (average values 0.45 and 0.55 , respectively, $P<0.005)$.

\section{Introduction}

This review focuses on the two major invasive techniques, angiocardiography and indicator dilution, both of which were introduced into the catheterization laboratory in the early $1960 \mathrm{~s}^{[1,2]}$. Purely qualitative or semi-quantitative modalities of angiographic and dilution techniques will not be dealt with here.

Quantification of valvular regurgitations by angiocardiography

MITRAL AND AORTIC REGURGITATION

Sandler $e t a l .^{[1]}$ were the first to quantify mitral or aortic regurgitation by means of angiocardiography. Angiographic determination of left ventricular total stroke volume (TSV) and forward stroke volume (FSV) obtained by a different technique are compared to

Supported by the Swiss National Science Foundation. estimate the regurgitant stroke volume (RSV) per beat $($ RSV $=$ TSV-FSV). The regurgitation fraction $(f)$ is calculated as RSV/TSV. Several limitations and sources of error of this technique have to be addressed:

(1) Determination of RSV across the mitral or the aortic valve is only possible when the other valve is competent. In the presence of mitral and aortic regurgitation RSV calculated according to the above formula equals the sum of the regurgitant flow in systole through the mitral valve and the regurgitant flow in diastole through the aortic valve.

(2) Ideally TSV and FSV should be determined simultaneously. However, angiographic contrast dye alters the circulatory dynamics after a few beats following injection and hence there is no steady state which should exist during the inscription (15 to 25 seconds) of a dye dilution curve or during the even longer Fick procedure for the estimation of cardiac output. Thus 
dye dilution or Fick cardiac output is determined prior to angiocardiography. Similar heart rates during cardiac output estimation and angiocardiography are generally taken as an indicator that the cardjovascular dynamics have been stable although this is no absolute proof that the amount of regurgitant volume was unchanged during the two measurements. Discrepancies in heart rate between cardiac output determina. tion and angiocardiography occur mostly in patients with atrial fibrillation. The error in determination of cardiac output by Fick or indicator dilution has been estimated to be between 5 and $10 \%{ }^{[3]}$.

(3) Of crucial importance for the validity of the combined technique based on the estimation of TSV and FSV is the accuracy with which angiographic TSV is determined. In 1966 Bartle and Sanmarco[4] $^{[4}$ have reviewed a number of studies in humans and experimental animals without regurgitation which compared angiographic stroke volume (SV-A) with SV obtained by conventional Fick or indicator dilution techniques. In the average angiocardiography overestimated stroke volume by about $15 \%$. We have reassessed the accuracy of angiographic stroke volume estimation in 16 patients with atypical chest pain or coronary artery disease but without valvular regurgitation or shunt. Fick cardiac output was determined first. $\mathrm{O}_{2}$ consumption was determined in 1 minute intervals during 10 minutes using a paramagnetic method (Oxycon Analyzer Mijnhardt BV, Odijk, Holland). After 5 minutes blood samples were withdrawn from the pulmonary artery and the aorta. The arterio-venous difference in $\mathrm{O}_{2}$ content was calculated from the $\mathrm{O}_{2}$ saturations and the actual hemoglobin assuming that $1 \mathrm{~g}$ hemoglobin contains $1.34 \mathrm{ml} \mathrm{O}$. Heart rate was assessed when blood samples were taken. Thereafter left ventricular biplane cineangiocardiography was performed in the right (RAO) and left (LAO) anterior oblique projection and enddiastolic and end-systolic volumes were calculated using the area-length method ${ }^{(9)}$. Both volumes were corrected by the regression equation proposed by Wynne et $a l^{[6]}$ for biplane RAO and LAO cineangiograms $\left(\mathrm{V}_{\text {true }}=0.989 \mathrm{~V}_{\mathrm{calc}}-8.1 \mathrm{ml}\right)$. Heart rate averaged $64 \mathrm{bpm}$ at both Fick and angiographic determinations whereas the individual differences varied between +7 and $-10 \mathrm{bpm}$. SV-A averaged $98 \mathrm{ml}$ and SV-Fick $83 \mathrm{ml}$ resulting in an $18 \%$ overestimation of stroke volume by angiocardiography (Fig. 1). The major reason for the overestimation of SV-A appears to be an underestimation of end-systolic volume although we were careful to trace always the outermost contour of the end-systolic silhouette $\mathrm{e}^{[7]}$. Corrections based on comparisons with casts ${ }^{[6]}$ had

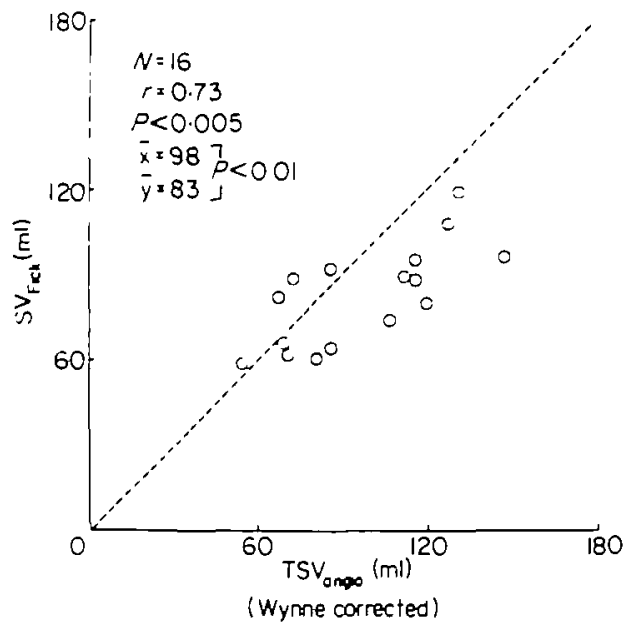

Figure 1 Comparison between stroke volume calculated from Fick cardiac output ( $\mathrm{SV}_{\text {Fick }}$ ) and stroke volume obtained by left ventricular biplane cineangiography (TSV angro $_{\text {) }} 16$ patients without shunt or valvular regurgitation. On average, cineangiography overestimated stroke volume by $18 \%$, and overestimation became apparent especially when stroke volume exceeded $100 \mathrm{ml}$. TSV anslo was calculated from end-diastolic and end-systolic volumes corrected according to the regression equation of Wynne et al. ${ }^{[6]}$.

resulted in only minor reductions of calculated stroke volume because the reduction of the end-diastolic volume by the regression equation was only slightly greater than that of the end-systolic volume.

\section{TRICUSPID AND PULMONIC REGURGITATION}

The same principle as for the quantification of the left-sided regurgitations by angiocardiography can be applied to calculate tricuspid or pulmonic regurgitant volume. However, right ventricular angiography is rarely used to quantitate tricuspid regurgitation ${ }^{[8]}$ and we are not aware of studies which tried to assess quantitatively pulmonic regurgitation.

In both tricuspid and pulmonic regurgitation accurate quantification of right ventricular enddiastolic and end-systolic volume is the prerequisite to obtain the total right ventricular stroke volume. Because right ventricular geometry is complex correction of the calculated volumes by a regression equation established from volumetric measurements of casts is of utmost importance. In the antero-posterior (AP) and lateral (LAT) or RAO and LAO projections calculated cast volumes correlated best with true volumes when the multiple slices method was applied for volumetric measurement. Whereas in the biplane AP/LAT projection true volumes of the casts were about $25 \%$ smaller than the calculated volumes ${ }^{\left[{ }^{8}\right]}$, the 
volumes correlated very closely in an almost $1: 1$ relationship when the casts were filmed in the RAO and $\mathrm{LAO}$ projections ${ }^{[9]}$. Hence proper positioning of the patient within the orthogonal $X$-ray beams and use of the projection-specific regression equation for correction of calculated volumes (by Simpson's rule) are mandatory.

In patients without right-sided regurgitant lesions or left to right shunts Gentzler et al ${ }^{[8]}$ have compared right ventricular SV-A with the SV derived from dye dilution cardiac output measurements performed 30 seconds prior to angiography. Right ventricular volumes were calculated from AP/LAT cineangiograms with the use of the multiple slices method and correction by the proper regression equation. An excellent correlation $(r=0.98)$ with almost identical mean values of the two stroke volumes was observed. Hence the authors have used the angio-indocyanine green method for quantitating tricuspid insufficiency in 6 cases $^{[8]}$. In contrast to the biplane right ventricular cineangiography the single plane RAO technique is less suitable for the assessment of tricuspid regurgitation because it overestimates right ventricular total stroke volume by about $20 \%{ }^{[10]}$.

\section{Quantification of valvular regurgitations by indicator dilution techniques}

In the early 1960s dye dilution techniques for the quantification of mitral and aortic regurgitation have been developed by Lacy et al. ${ }^{[1]}$ and the Mayo Clinic Group headed by E. H. Wood ${ }^{[12-14]}$. The technique is based on the recording of simultaneous dilution curves upstream and downstream to the incompetent valve following injection of the indicator just downstream to this valve. If the two dilution curves are sampled by equisensitive devices (cuvette densitometers for dye dilution, thermistors for thermodilution) the regurgitant flow $\left(Q_{R}\right)$ is determined by the following formula:

$$
Q_{R}=\frac{Q_{F}}{\left(\frac{A_{\text {down }}}{A_{\text {up }}}-1\right)},
$$

where

$Q_{F}=$ forward flow (cardiac ouput in $1 \mathrm{~min}^{-1}$ ),

$Q_{R}=$ regurgitant flow (in $1 \mathrm{~min}^{-1}$ ),

$A_{\text {down }}=$ area of the downstream dilution curve,

$A_{\text {up }}=$ area of the upstream dilution curve.

In the case of mitral regurgitation the indicator is injected into the left ventricle; $A_{\text {down }}$ corresponds to the dilution curve recorded in the descending aorta $\left(A_{A O}\right)$ and $A_{p p}$ to that recorded in the left atrium $\left(A_{L A}\right)$.
For the quantification of aortic regurgitation the indicator is injected into the aortic root; $A_{\text {down }}$ corresponds to the dilution curve recorded in the descending aorta $\left(A_{A O}\right)$ and $A_{u p}$ to that recorded in the left ventricle $\left(A_{L v}\right)$. The mitral regurgitation fraction $\left(f_{m}\right)$ equals $A_{L A} / A_{A O}$ and the aortic regurgitation fraction $\left(f_{\text {Eo }}\right) A_{L V} / A_{A O}$. These relationships hold regardless whether only the valve in question or both left-sided valves are incompetent.

In the presence of combined mitral and aortic regurgitation the combined regurgitation fraction $\left(f_{c}\right)$ is obtained by the sampling of simultaneous dilution curves in the left atrium $\left(A_{L A}\right)$ and the descending aorta $\left(A_{A O}\right)$ after indicator injection into the aortic $\operatorname{root}^{[15]}$.

$$
\mathrm{fc}=\frac{A_{L A}}{A_{A O}}=f_{m} \cdot f_{m o} .
$$

Thus from the combined regurgitation fraction and the regurgitation fraction of one of the two incompetent valves the regurgitation fraction of the second valve can be calculated. In patients with mitral and aortic regurgitation Bloomfield et al. ${ }^{[15]}$ have documented a close correlation $(r=0.99)$ between $f_{c}$ and the product of the individually determined regurgitation fractions across the mitral and the aortic valve.

\section{ADVANTAGES AND LIMITATIONS}

In contrast to the angiographic technique the dilution methods with upstream and downstream sampling allow simultaneous estimation of forward and regurgitant flow. The accuracy of the determination of the forward cardiac output is well established ${ }^{(3)}$. Repeated estimations of $f_{m}$ and $f_{2 o}$ are possible because the indicators are devoid of cardiovascular effects. The indicator dilution methods are, however, dependent on thorough mixing of the regurgitant volume with the untagged blood in the upstream chamber. If mixing is incomplete the area of the regurgitation dilution curve may vary sizably at different sampling sites in the upstream chamber ${ }^{[12,16]}$. Especially in mild regurgitations indicator concentration in the upstream chamber may be higher at sampling sites close to the insufficient valve than in more remote portions of the chamber.

COMPARLSON OF THE INDICATOR DILUTION TECHNIQUE WITH AN INDEPENDENT METHOD FOR THE QUANTIFICATION OF MITRAL AND AORTIC REGURGITATION

Experimental studies

Several studies by the Mayo Clinic Group have 
compared the regurgitant flow obtained by dye dilution with the regurgitant flow determined by an independent method ${ }^{[12-14]}$. In dogs with artificially produced chronic mitral insufficiency the regurgitant flow by the indocyanine dye technique correlated closely $(r=0.96)$ with the regurgitant flow estimated by an hydraulic technique based on the mean systolic pressure gradient across the mitral valve (measured just before dye injection), the systolic regurgitant time and the defect area in the anterior mitral leaflet determined at necropsy ${ }^{[12]}$. In dogs with acute regurgitation a positive correlation existed between the aortic regurgitation fraction determined by dye dilution and the ratio of regurgitant volume/total stroke volume assessed from phasic recording of blood flow in the ascending aorta by an electromagnetic flowmeter ${ }^{[14]}$. The dye dilution regurgitation fraction was slightly but systematically larger than the aortic regurgitation fraction obtained from the flowmeter recording. The overestimation of regurgitant flow was, however, small in mild and moderately severe aortic regurgitation and became more marked only at regurgitation fractions of 0.60 or more $e^{[14]}$.
Comparison in patients with aortic or mitral regurgita tion

In 23 patients with isolated aortic and 23 patients with isolated mitral regurgitation $f_{\text {so }}$ and $f_{m}$ were determined by thermodilution using upstream and downstream sampling with respect to the incompetent valve according to the technique described previously ${ }^{[16.17]}$. The regurgitation fractions obtained by thermodilution were compared with $f_{m o}$ and $f_{m}$ estimated by the combined angio-Fick method. Figure 2 shows an example of the recording of simultaneous dilution curves with equisensitive thermistors in the left ventricle and the descending aorta in a patient with aortic regurgitation. All patients with aortic regurgitation and $10 / 23$ patients with mitral regurgitation were in sinus rhythm. The other 13 patients with mitral regurgitation had atrial fibrillation.

Fick cardiac output was determined first (see the previous section on quantification by angiocardiography). $\mathrm{O}_{2}$ consumption $\left(\mathrm{VO}_{2}\right)$ was measured in $36 / 46$ patients by the Oxycon analyzer. In 10 patients $\mathrm{VO}_{2}$ was taken from a nomogram* assuming a basal * Documenta Geigy, Scienufic Tables. Sth ed, Baste. 1955. 241

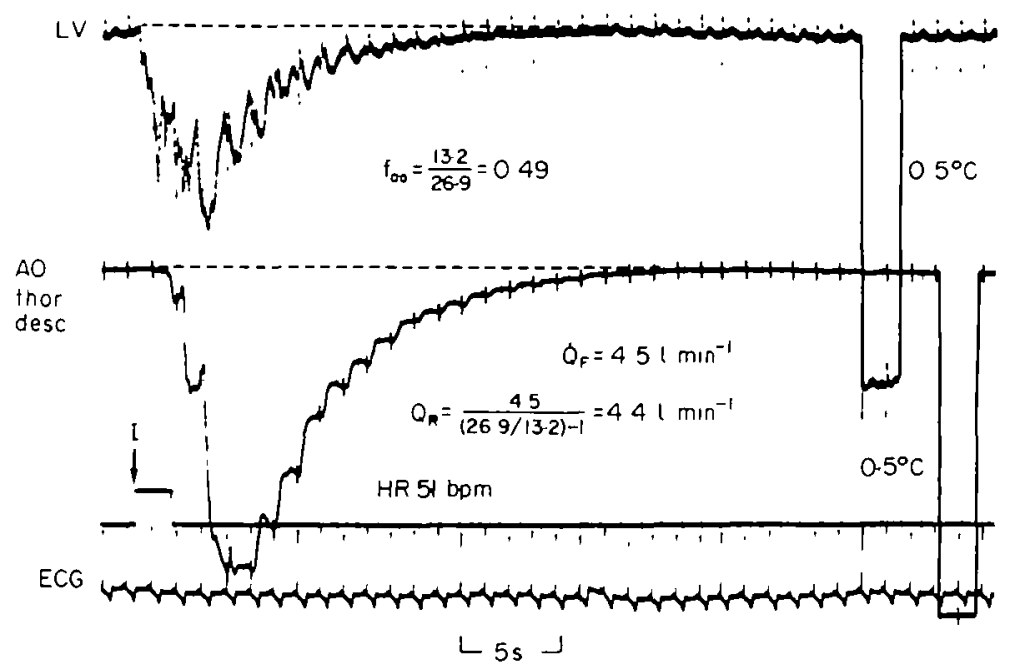

Figure 2 Recording of simultaneous thermodilution curves with equisensitıve thermistors ( $3 \cdot 5 \mathrm{~F})$ in the left ventricle and in the descending thoracic aorta following injection of $10 \mathrm{ml}$ icecold saline in a patient with aortıc regurgitation. The thermistor in the left ventricle was advanced through a $8.5 \mathrm{~F}$ transseptal Brockenbrough catheter. The other thermistor was advanced through a black Kifa catheter inserted into the left femoral artery. Cold salıne was injected into the aortic root via a $8 \mathrm{~F}$ ptgtail catheter inserted through the right femoral artery. The aortic regurgitation fraction $\left(f_{m o}\right)$ was obtained from the ratio of the areas of the two thermodilution curves (areas in $\mathrm{cm}^{2}$ ). Aortic regurgitant flow ( $\dot{Q}_{k}$ ) was calculated from the forward cardiac output $\left(Q_{F}\right)$ and the ratio of the areas of the two thermodilution curves. In the figure, I is the point when $10 \mathrm{ml}$ icecold saline was injected into the aortic root. LV is the left ventricle, AO thor desc is the descending thoracic aorta. HR is heart rate, and ECG is electrocardiogram. 


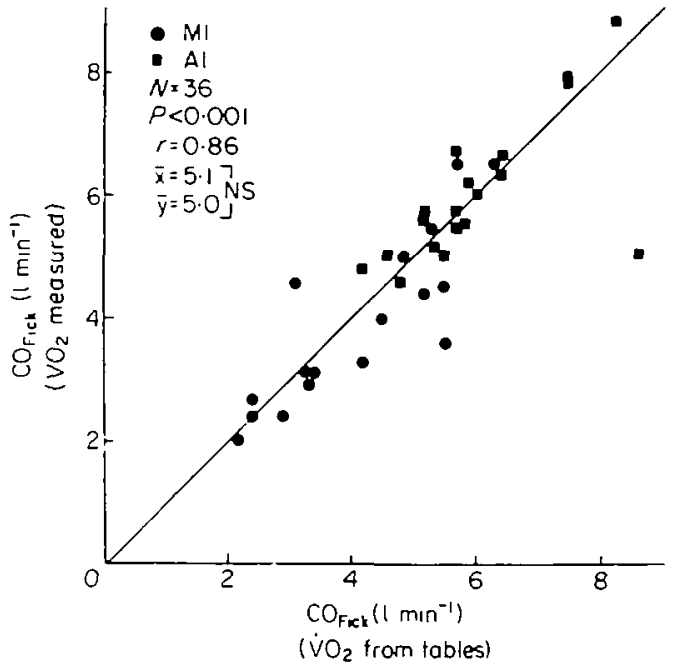

Figure 3 Comparison between Fick cardiac output $\left(\mathrm{CO}_{\text {Fick }}\right)$ calculated with measured $\mathrm{O}_{2}$ consumption and Fick cardiac output calculated with $\mathrm{VO}_{2}$ taken from a nomogram in 19 patients with aortic insufficiency (AI) and 17 patients with mitral insufficiency (MI). There was good agreement between the two values of cardiac output $(r=0.86) . \mathrm{VO}_{2}$ is the oxygen consumption.

metabolism of $+5 \%$ of normal. We accepted these values from the nomogram because in 36 patients Fick cardiac output calculated with measured $\mathrm{VO}_{2}$ correlated closely $(r=0-86)$ with cardiac output calculated with $\mathrm{VO}_{2}$ taken from tables (Fig. 3).

After the Fick cardiac output estimation the thermodilution study was performed. On average, $3 \cdot 3$ pairs (upstream and downstream sampling) of thermodilution curves per patient were recorded. The areas of the curves were obtained by planimetry. Quantification for the cold injection was carned out by a model experiment using the same injection catheter and the same quantity of icecold saline ( 10 $\mathrm{ml}$ ) as in the in vivo situation ${ }^{(16-17]}$. Finally biplane left ventricular cineangiography was performed in the RAO and LAO projections ${ }^{|5|}$. Heart rate in the 23 patients with aortic regurgitation averaged 73,71 and $74 \mathrm{bpm}$ during the three investigations. Individual differences of heart rate exceeded $10 \mathrm{bpm}$ in 5 of the 69 possible paired comparisons. Heart rate in the 23 patients with mitral regurgitation averaged 77,76 and $78 \mathrm{bpm}$ during Fick, thermadilution and cineangiography, respectively. In 3 of 69 paired comparisons the difference in heart rate was larger than $10 \mathrm{bpm}$.

The left ventricular total stroke volume was

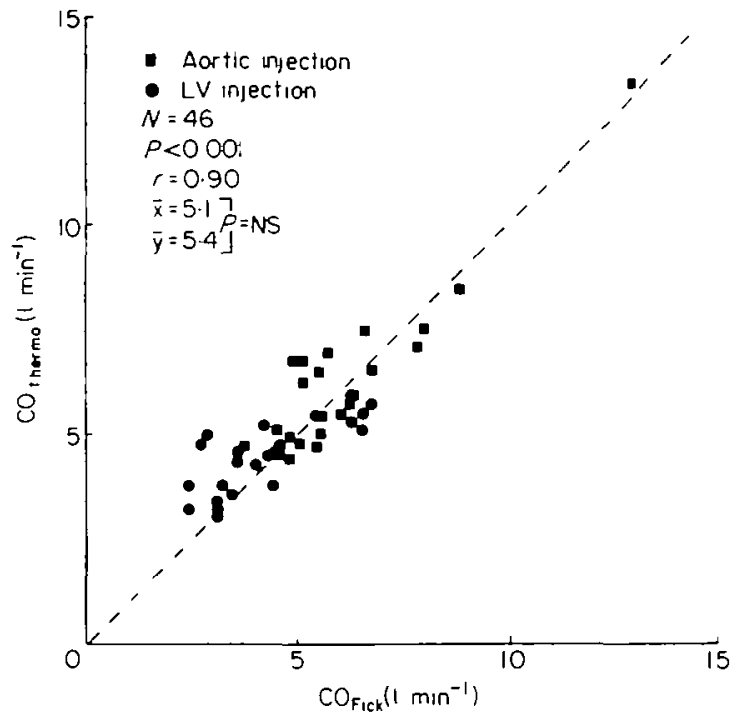

Figure 4 Comparison between cardiac output determined by thermodilution ( $\mathrm{CO}_{\text {thermo }}$ ) and cardiac output determined by the Fick method ( $\mathrm{CO}_{\text {Fick }}$ ) in 23 patients with aortic regurgitation (AR, squares) and 23 patients with mitral regurgitation ( $M R$, dots). In AR cold saline was injected into the aortic root and in MR into the left ventricle. Thermo dilution sampling was performed in the descending thoracic aorta. There was good agreement between the two techniques regardless of the injection site of the cold indicator.

obtained as the difference of the angiographic enddiastolic volume minus the end-systolic volume after both volumes had been corrected by the regression equation of Wynne et al. ${ }^{[6]}$. In addition the calculated total stroke volume was corrected for the $18 \%$ overestımation by biplane cineangiography (see Fig. 1). The forward stroke volume (FSV) which was used to calculate angiographic regurgitant volume and regurgitation fraction was obtained as Fick cardiac output/heart rate existing at the time of cineangiography. The choice to use FSV obtained by the Fick method rather than by thermodilution cardiac output was motivated by our aim to compare the indicator dilution technique with a truly independent (angio-Fick) method although there was no significant difference between cardiac output determined by thermodilution and that obtained by the Fick method (Fig. 4).

In the patients with isolated aortic regurgitation there was a positive correlation between $\mathrm{f}_{\mathbf{z}}$ evaluated by thermodilution and $f_{20}$ determined by the angioFick method, $r=0.59$ (Fig. 5). Although the mean value of $f_{\infty}$ by angio-Fick was somewhat higher than 


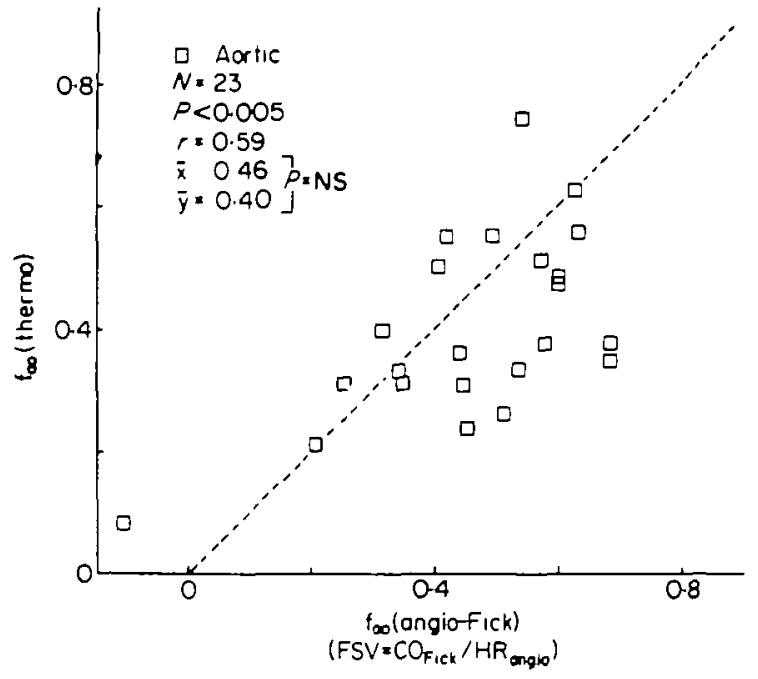

Figure 5 Comparison between aortic regurgatation fraction ( $f_{\text {so }}$ ) determined by thermodilution and $f_{\text {mo }}$ obtained by the combined angiographic-Fick method in 23 patients with aortic regurgitation. For the calculation of $\mathrm{f}_{\text {so }}$ (angio-Fick) forward stroke volume (FSV) was calculated from Fick cardiac output ( $\mathrm{CO}_{\text {Fick }}$ ) divided by heart rate existing at angiography (HR anto). We used this particular heart rate in order to compensate for differences (although small) between heart rate during Fick and during angiography. It was assumed that forward cardiac output remained stable dunng the small variations of heart rate. The total angiographic stroke volume (TSV) was calculated from end-diastolic and end-systolic volumes corrected according to the Wynne regression equation ${ }^{[6]}$; the value obtained was reduced in accordance with the average overestimation $(18 \%)$ of stroke volume by angiography as shown in Fig. 1.

The mean values of $f_{\text {to }}$ (thermo) and $f_{\text {no }}$ (angio-Fick) were not significantly different, although there was a tendency for $f_{a 0}$ (angio-Fick) to be larger than $f_{20}$ (thermo). There was only a fair correlation $(r=0.59)$ between the two measurements. In one patient aortic regurgitation was missed by the combined angio-Fick method.

that of $\mathrm{f}_{\mathrm{a}}$ determined by thermodilution the difference was not significant. In the patients with isolated mitral regurgitation there was also a positive correlation between $f_{m}$ as determined by thermodilution and $f_{m}$ assessed by angio-Fick, the $r$ value being 0.71 (Fig. $6) ; f_{m}$ by thermodilution was, however, significantly smaller than $f_{m}$ obtained by angio-Fick.

COMPARISON OF TOTAL LEFT VENTRICULAR STROKE VOLUME DETERMINED BY THERMODILUTION AND CINEANGIOGRAPHY IN PATIENTS WITH COMBINED AORTIC AND MITRAL REGURGITATION

In 18 additional patıents with combined aortic and

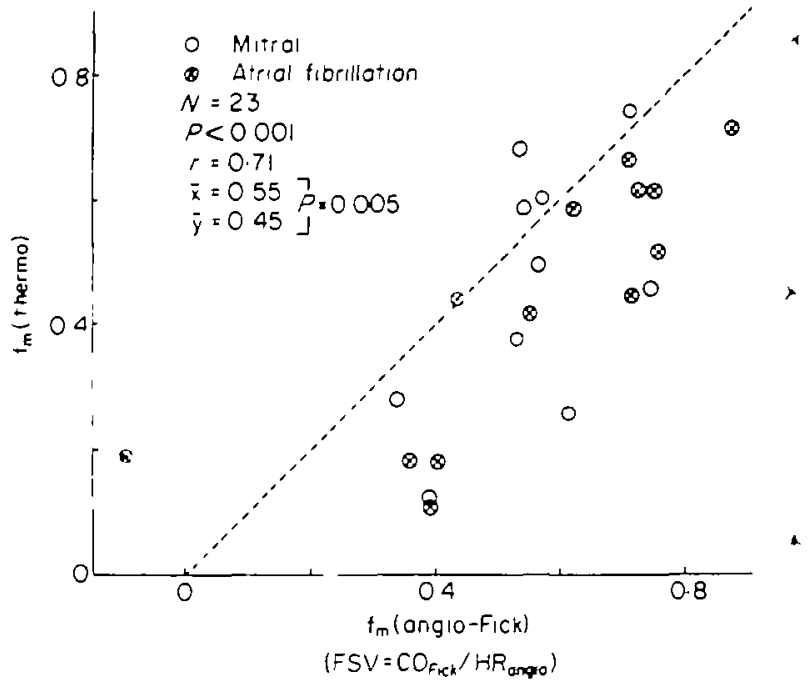

Figure 6 Comparison between mitral regurgitant fraction $\left(f_{m}\right)$ determined by thermodilution and $f_{m}$ determined by the angio-Fick method in 23 patients with isolated mitral regurgitation. The forward stroke volume (FSV) and the left ventricular angiographic total stroke volume (TSV) were determined as outlined in Fig. 5. There was a positive correlation between the two measurements although $f_{m}$ determined by angio-Fick was significantly larger than $f_{m}$ estımated by thermodilution. In one patient mitral regurgitation was missed by the combined angio-Fick technique. (Results for patients in atrial fibrillation are indicated by a circle with a cross.)

mitral regurgitation $f_{\infty}$ and $f_{m}$ were determined individually by thermodilution. In 6 of the 18 patients atrial fibrillation was present. First it was evaluated whether cardiac output determined from the area of the thermodilution curve in the descending aorta was different when cold injection occurred in the aortic root rather than in the left ventricle. As demonstrated in Fig. 7 forward cardiac output was uninfluenced by the site of injection of the indicator. After having determined the individual regurgitations across the aortic and the mitral valves, total left ventricular stroke volume was calculated. The two values obtained in an individual patient according to the cardiac output determination following cold injection into the aortic root or the left ventricle were averaged. These mean values showed a good correlation with left ventricular total stroke volume determined by biplane cineangiography (Fig. 8). A comparison of regurgitation fractions between the two techniques could not be performed because individual regurgitations cannot be quantified by the angio-Fick method in patients with combined valvular lesions. 


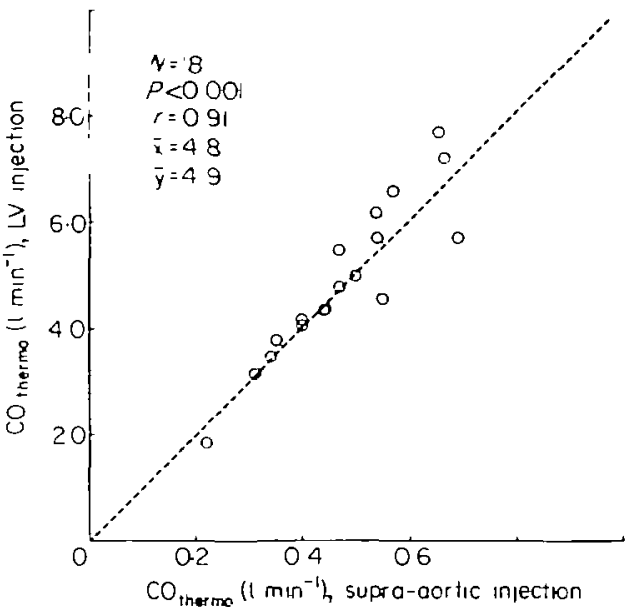

Figure 7 Comparison between cardiac output obtained by thermodilution following indicator injection into the left ventricle and cardiac output by thermodilution followng indicator injection into the aortic root in 18 patients with combined mitral and aortic regurgutation.

There is an excellent agreement $(r=0.91)$ between the two measurements. Hence the estimation of forward cardiac output was uninfluenced by the site of indicator injection.

COMMENTS ON THE COMPARISON OF THERMODILUTION WITH CINEANGIOGRAPHY FOR THE QUANTIFICATION OF VALVULAR REGURGITATIONS IN MAN

As outlined above similar values of $f_{40}$ were obtained by thermodilution and the angio-Fick method although the correlation between the two techniques was at best fair. In the patients with isolated mitral regurgitation $f_{m}$ was significantly larger with angio-Fick than with thermodilution. Several factors may be responsible for these findings. First the comparison between the two independent techniques was not done simultaneously. For large cineangiographic total stroke volumes, the $18 \%$ correction we have performed according to the average difference observed between angiographic and Fick derived stroke volume in patients without valvular regurgitation or shunt was probably too small because it is evident from Fig. 1 that overestimation by angiography was more marked at larger stroke volumes. This would have resulted in an overestimation of angiographic regurgitation fractions. Another problem includes angiographic beat selection in atrial fibrillation. The total stroke volume of the chosen beat may not be the same as during the inscription of the thermodilution curves despite good agreement between the average heart rate during

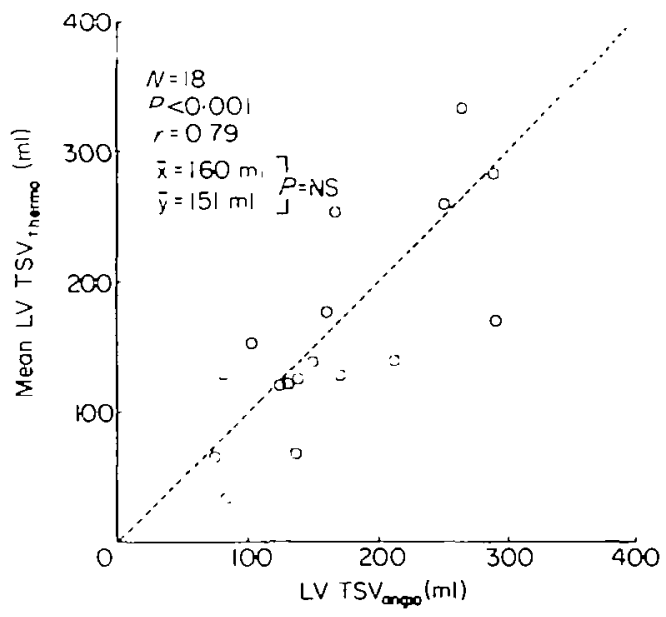

Figure 8 Comparison between left ventricular total stroke volume determined by thermodilution and left ventricular total stroke volume determined by biplane cineangiography in 18 patients with combined mitral and aortic regurgitation. With thermodilution, mitral and aortic regurgitation fractions were determuned individually for both valves in each patient. In the individual patients left ventricular total stroke volume (LV TSV) determined by thermodilution represents the mean of two calculations, one from the cardiac output obtained after indicator injection into the aortic root and one from the cardiac output measure following indicator injection into the left ventricle. The LV TSV therwo agreed quite well with the LVTSV ano $(r=0 \cdot 79)$. This may be taken as indirect evidence of the validity of the thermodilution technıque for assessing quantitatıvely aortic and mitral regurgitations. LV TSV anqo was corrected according to the Wynne regression equation ${ }^{[6]}$; the value obtained was reduced in accordance with the average overestimation (18\%) of stroke volume by angiography (see Fig. I).

thermodilution and the heart rate corresponding to the cycle interval preceding the beat chosen for estimation of angiographic stroke volume. Errors in the quantification of mitral regurgitation with thermodilution may also have occurred and are likely to be linked to errors in left atrial indicator concentration sampling due to inadequate mixing. Finally, we have to consider that in Fick cardiac output determination of patients with atrial fibrillation average heart rate may not correspond with average forward stroke volume. Alternatively indirect evidence for the validity of thermodilution for the quantification of regurgitation may be derived from the good agreement of total left ventricular stroke volume estimated by thermodilution with total angiographic stroke volume in patients with combined aortic and mitral regurgitation. 
RECENT DEVELOPMENT OF EQUIPMENT FOR THE ESTIMATION OF MITRAL AND AORTIC REGURGITATION BY THERMODILUTION

The thermodilution studies outlined above required the insertion of two thermistor probes $(3.5 \mathrm{~F})$ one into the left atrium and/or the left ventricle via a transseptal 8.5 F Brockenbrough catheter and the other into the descending aorta via the retrograde femoral route ${ }^{[17]}$. Cold saline was injected into the left ventricle or aortic root through a pigtail catheter inserted via the other femoral artery. Recently this procedure was simplified ${ }^{(18)}$. A double-lumen polyethylene pigtail catheter $(8 \mathrm{~F}, 100 \mathrm{~cm})$ is inserted into the right femoral artery and is advanced to the left ventricle or aortic root. Through the distally ending lumen $\left(0.8 \mathrm{~mm}^{2}\right)$ cold saline is injected. Through the second lumen $\left(0.8 \mathrm{~mm}^{2}\right)$ which opens $50 \mathrm{~cm}$ behınd the catheter tip a thermistor probe $(3 \mathrm{~F}$, tefion) is advanced into the descending aorta for the recording of thermodilution curves. The second thermistor is again inserted via the transseptal Brockenbrough catheter.

\section{Summarizing remarks}

From this summary on the anglographic and indicator dilution techniques for the quantification of valvular regurgitations, it may be concluded that: (1) both techniques are based on sound principles; (2) they have been used so far almost exclusively for the quantification of mitral and aortic regurgitation and (3) they have several drawbacks:

The angographic technique tends to overestimate total left ventricular stroke volume and hence regurgitation fraction; it requires the estimation of forward stroke volume by another non-simultaneous technique with its own sources of error; it cannot be used for the quantification of individual valvular regurgitations when both the aortic and the mitral valves are incompetent and alterations of cardiovascular dynamics following contrast dye injection limit repeated angiographıc quantifications of regurgitation. Thus the place of the angiographic technique as the gold standard for the quantification of valvular regurgitations may be debated.

The indicator dilution techniques (indocyanine green, thermodilution) are crucially dependent on thorough mixing of the regurgitant volume with the blood in the upstream chamber. Thus the recorded indicator concentrations may vary according to the specific sampling site within this chamber. Slight regurgitations into a large upstream chamber (especially the anatomically ill-defined upstream mixing chamber in mitral regurgitation) are most likely to be erroneously assessed by dilution techniques.

\section{References}

[1] Sandler H. Dodge HT, Hay RE, Rackley CE. Quantitation of valvular insufficiency in man by anglocardiography. Am Heart J 1963; 65: 501-13.

[2] Wood EH. Speculations concerning present and future developments in indicator-dilution technics In: Symposium on use of indicator-dilution technies in the study of circulation Am Heart Ass Monograph 4. New York, 1962: 569-81

[3] Grossman W. Blood flow measurement: The cardiac output In Cardiac catheterization and angiography, 2nd edition. Philadelphia Lea and Febiger, 1980 89-102

[4] Bartle SH, Sanmarco ME. Comparison of angiocardiographic and thermal washout technics for left ventricular volume measurement. Am J Cardiol 1966; 18. 235-52.

[5] Eichhorn P, Grimm J, Koch R, Hess O, Carroll J, Krayenbuehl HP Left ventricular relaxation in patients with left ventricular hypertrophy secondary to aortic valve disease. Circulation 1982, 65: 1395-404.

[6] Wynne J, Green LH, Mann T, Levin D, Grossman W. Estımation of left ventricular volumes in man from biplane crneangiograms filmed in oblique projections. Am J Cardiol 1978, 41: 726-32.

[7] Sandler H. Dimensional analysis of the heart. A review Am J Med Sci 1970, 260: 56-70.

[8] Gentzler RD, Briselli MF, Gault JH. Angrographic estimation of right ventricular volume in man. Circulation 1974; 50. 324-30.

[9] Hess OM, Goebel NH, Grımm J, Krayenbuehl HP Accuracy of angiographic right ventricular volume determination. In: Kaltenbach $\mathrm{M}$, Lichtlen $\mathrm{P}$, Balcon R. Bussmann WD, eds. Coronary heart disease Stuttgart. G. Thieme, 1978: 22732.

[10] Ferlinz J. Right ventricular performance in essential hypertension. Circulation 1980; 61: 156-62.

[11] Lacy WW, Goodson WH, Wheeler WG, Newman EV. Theoretical and practical requirements for the valid measurement by indicator-dilution of regurgitant flow across incompetent valves. Circ Res 1959, 7: 454-60.

[12] Newcombe CP. Sinclair JD, Donald DE, Wood EH. Detection and assessment of mitral regurgitation by left atrial indicator-dilution curves. Circ Res 1961; 9: 1196-207

[13] Armelin E, Michaels L, Marshall HW, Donald DE, Cheesman RJ, Wood EH. Detection and measurement of experimentally produced aortic regurgitation by means of indicator-dilution curves recorded from the left ventricle. Circ Res 1963; 12: 269--90.

[14] Malooly DA, Donald DE, Marshall HW, Wood EH. Assessment of an indicator-dilution technic for quantitatıng aortic regurgitation by electromagnetuc flowmeter Circ Res 1963; 12: 487-507.

[15] Bloomfield DA, Battersby EJ, Sinclair-Smith BC. Use of indicator dilution techniques in measuring combined aortic and mitral insufficiency. Circ Res 1966; 18: 97100 
[16] Krayenbūhl HP. Die Dynamik und Kontraktilitāt des linken Ventrikels. Bibl Cardiol 23. Basel: S Karger, 1969: $1-182$.

[17] Krayenbühl HP, Rutishauser W, Wirz P, Noseda G, Lüthy E. Das enddiastolische Volumen der linken Kammer beim Menschen, bestimmt mit der Thermo- dilutionsmethode. Arch Kreislaufforschg 1969; 58: $1-35$.

[18] Krayenbūhl HP, Niederhauser W, Grimm J, Hirzel H, Hess $O$. Ein neuer Thermodilutionskatheter zur Bestimmung des Heruminutenvolumens im arteriellen System. Schwe1z med Wochenschr 1984; 114: 1604-6. 